\title{
Development of a ZnO-modified Light-Scattering Sensor for the Detection of Alcohols
}

\author{
Song-Ji NIAN and Jyisy Y ANG $^{\dagger}$ \\ Department of Chemistry, National Chung-Hsing University, Taichung 402, Taiwan
}

\begin{abstract}
A light-scattering sensor that incorporated zinc oxide $(\mathrm{ZnO})$ nanoparticles was developed and characterized in this study. Evenly distributed nanostructured $\mathrm{ZnO}$ materials were formed on the sensing elements through the calcination of zinc acetate-treated sensing elements in a high-temperature oven. There was a large change in the scattering properties of the nanostructured $\mathrm{ZnO}$ materials after adsorption of the target compounds; this behavior was exploited for quantitative purposes. To investigate the detection of volatile compounds using this method, both static and flow cell-type devices were constructed. To determine the most suitable nanostructured $\mathrm{ZnO}$ material for the light scattering sensors, several factors that influenced their morphologies, including the calcination temperature, calcination time, and the amount of $\mathrm{ZnO}$ colloidal solution for calcination, were examined. Fiber-like $\mathrm{ZnO}$ structures were produced at temperatures below $400^{\circ} \mathrm{C}$. Above $400^{\circ} \mathrm{C}$, particles having round shapes were observed; the higher the calcination temperature, the larger the particle sizes. Based on an examination of the signals from several volatile organic compounds, the prepared $\mathrm{ZnO}$ sensor was selective for the detection of alcohols, and the observed signals followed the surface-adsorption mechanism. The prepared sensor is fast in response, and the detection time can be shorter than 2 min. For quantitative purposes, the linear range was limited to low concentrations of alcohols, i.e., up to $c a$. $200 \mathrm{ppm}$.
\end{abstract}

(Received November 20, 2009; Accepted January 16, 2010; Published April 10, 2010)

\section{Introduction}

$\mathrm{ZnO}$ exhibits unique chemical properties, and can exist in a wide range of nanostructural forms. ${ }^{1}$ Nanostructured $\mathrm{ZnO}$ materials can be prepared in the form of nanoparticles, ${ }^{2,3}$ nanorods, ${ }^{4,5}$ nanowires, ${ }^{6,7}$ and other morphologies ${ }^{8,9}$ through the use of vapor deposition or wet chemical methods. These materials have been used in devices, such as field-effect transistors, ${ }^{10,11}$ solar cells ${ }^{12,13}$ and as photocatalysts. ${ }^{14-16}$ One of the most interesting uses of $\mathrm{ZnO}$ is in the field of sensing technology. For instance, taking advantage of the catalytic behavior of $\mathrm{ZnO}$, sensors have been developed for the detection of $\mathrm{NO}_{\mathrm{x}}{ }^{17}$ alkanes, ${ }^{18}$ ethers, ${ }^{19}$ amines, ${ }^{20-22}$ ketones, ${ }^{23-25}$ aromatic volatile compounds, ${ }^{26}$ and alcohols. ${ }^{27-31}$ Unfortunately, these sensors are typically operated at temperatures above $250^{\circ} \mathrm{C}$ to trigger catalytic reactions that allow electronic sensing. The need for extreme sensing conditions and catalytically reactive molecules limits the application of these types of detection systems. To increase the ability to detect under milder conditions, $\mathrm{ZnO}$ nanowires ${ }^{32}$ and $\mathrm{ZnO}$ nanoparticles ${ }^{33}$ have been prepared directly on the surfaces of infrared sensing elements; these systems allow for the highly sensitive detection of volatile organic compounds (VOCs) in gas atmospheres, particularly for those compounds bearing hydroxyl groups. ${ }^{33}$ To simplify the sensing system while utilizing the unique interactions between $\mathrm{ZnO}$ and alcohols, in this study we developed a light-scattering sensor. This device is simple in terms of the instrumentation required, and is effectively operational for the selective detection

$\dagger$ To whom correspondence should be addressed.

E-mail: jyisy@dragon.nchu.edu.tw of alcohols. Conceptually, the analytical signals in this new detection scheme are based on changes that occur to the light-scattering properties of $\mathrm{ZnO}$ particles after they have interacted specifically with the target compounds.

\section{Experimental}

Materials and reagents

Zinc acetate dihydrate (99.6\%, Sigma), 2-methoxyethanol (99.5\%, Riedel-De Haën), ethanol (anhydrous, J. T. Baker), and monoethanolamine (99\%, Riedel-De Haën) were used to prepare zinc colloidal solution. The six VOCs examined as analytes (chloroform, carbon tetrachloride, trichloroethylene (TCE), methanol, ethanol, and propanol) were obtained from Acros Organics (Geel, Belgium) in reagent grade.

\section{Apparatus}

Two sensing systems were prepared: a static system and a flow-cell system. Figure 1A displays a schematic illustration of the experimental setup for the static system. The volume of the cell was $70 \mathrm{~mL}$. To prevent gas molecules from leaking through or adsorbing onto the sample cap, the cap of this cell was formed from a thick Teflon film, a rubber pad, and a stainless-steel plate; it was tightened to the cell body using four screws. A quartz rod of diameter of $3 \mathrm{~mm}$ was placed at the center of the sample cell to direct the laser radiation. In the middle of the quartz rod, a region of $6 \mathrm{~mm}$ in length was further treated with $\mathrm{ZnO}$ nanoparticles to scatter the propagated laser radiation out of the quartz rod. A silicon detector (DP01-39, Duma Optronics) having a sensing area of $5 \mathrm{~mm}^{2}$ was used to detect the scattered radiation. A $660-\mathrm{nm}$ diode laser $(30 \mathrm{~mW}$, 

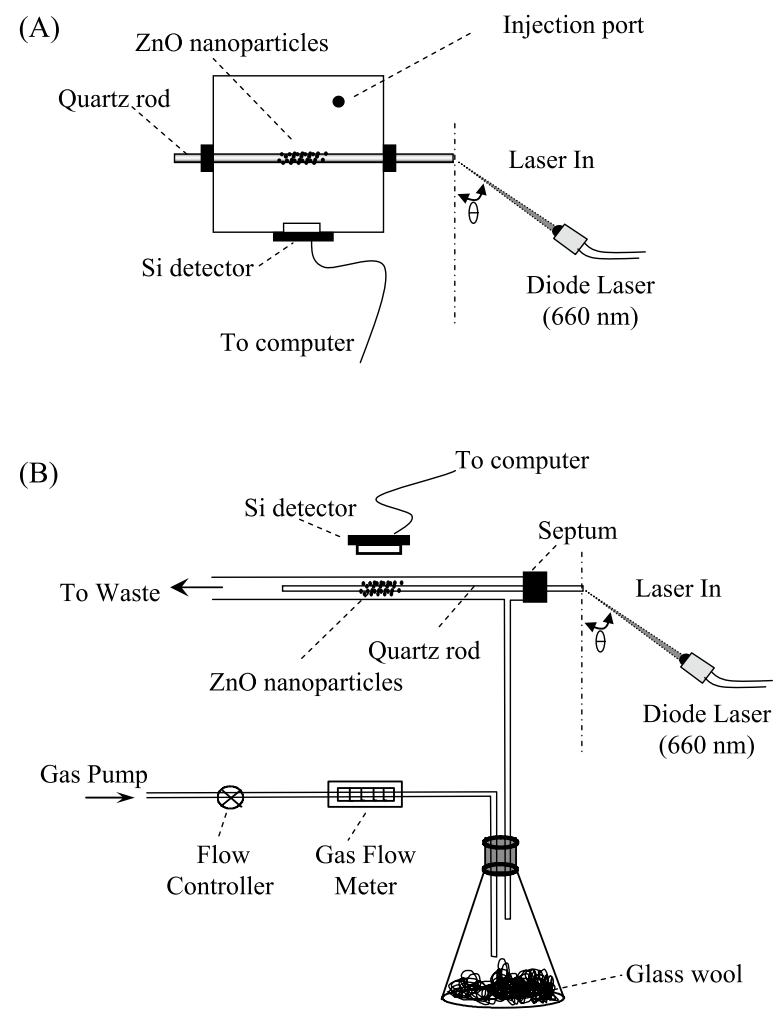

Fig. 1 Schematic illustrations of (A) static and (B) flow cell-type sensing systems.

E-Laser Enterprise, Taichung, Taiwan), used as radiation source, was operated at $4.5 \mathrm{~V}$ so as to increase its lifetime. Figure 1B provides a schematic illustration of the experimental setup of the flow-cell system; its components were the same as those in the static sensing system. Glass wool was placed at the bottom of 7-mL sample vial so as to reduce the flow pulse after injection of the samples into the flow cell.

Preparation of a zinc oxide colloidal solution and $\mathrm{ZnO}$-modified sensing element

A zinc colloidal solution was prepared using a modified sol-gel approach. Zinc acetate dihydrate was mixed with 2-methoxyethanol and ethanol (70:30, v/v), followed by the addition of monoethanolamine; the $\mathrm{Zn}^{2+}$-to-monoethanolamine molar ratio was 1:1. The final concentration of $\mathrm{Zn}^{2+}$ was $0.25 \mathrm{M}$. This mixture was heated at $70^{\circ} \mathrm{C}$ for $2 \mathrm{~h}$ to ensure the formation of a colorless solution.

Portions of the prepared zinc colloidal solution (volumes of 10 to $60 \mu \mathrm{L}$ ) were coated on a quartz rod (diameter: $3 \mathrm{~mm}$ ); the coated area had a length of $6 \mathrm{~mm}$. After drying for $30 \mathrm{~min}$ in a fume hood, the surface-coated sensing element was placed into a high-temperature furnace for calcination of the coated zinc solution. The calcination temperature, the volume of the coating zinc colloidal solution, and the calcination time were modified to determine their effects on the sensing properties and morphologies of the $\mathrm{ZnO}$ nanomaterials. Field emission scanning electron microscopy (FESEM), using a JSM-6700F microscope (JOEL, Japan), was employed to examine the morphologies of the $\mathrm{ZnO}$ nanoparticles.

\section{Results and Discussion}

Morphologies of the prepared $\mathrm{ZnO}$ nanostructural materials

To optimize the conditions for the preparation of suitable nanostructured $\mathrm{ZnO}$ materials for light-scattering sensing devices and to observe the morphologies of the materials prepared under different calcination conditions, $\mathrm{ZnO}$ solutions were calcined at various temperatures and for different calcination times. Figures $2 \mathrm{~A}$ to $2 \mathrm{C}$ display SEM images of $\mathrm{ZnO}$ solutions calcined at $300^{\circ} \mathrm{C}$ for $1,1.5$, and $2 \mathrm{~h}$. As can be seen in these images, non-regular fiber-like structures can be observed for the $\mathrm{ZnO}$ solution calcined at $300^{\circ} \mathrm{C}$; when the calcination time was extended to $2.5 \mathrm{~h}$, the morphologies of the resulting $\mathrm{ZnO}$ materials remained as non-regular fibers, but with decreased size. When the calcination temperature was raised to $400^{\circ} \mathrm{C}$ (Figs. 2D to $2 \mathrm{~F}$ ), the $\mathrm{ZnO}$ particles that formed had round shapes; extending the calcination time from 1 and $1.5 \mathrm{~h}$ increased the diameter of the nanoparticles slightly.

To further examine the effect of temperature on the formation of $\mathrm{ZnO}$ nanoparticles, SEM images (Figs. 2G to 2I) of the products of $\mathrm{ZnO}$ solutions calcined at 200,500 and $600^{\circ} \mathrm{C}$ for $1 \mathrm{~h}$ were further acquired. As can be seen in these images, the $\mathrm{ZnO}$ materials formed at calcination temperatures lower than $400^{\circ} \mathrm{C}$ tended to form in non-regular shapes. When the calcination temperature was higher than $400^{\circ} \mathrm{C}$, the nanoparticles that formed were round; a higher calcination temperature provided larger nanoparticles. This behavior presumably arose as a result of incomplete decomposition of the organic species in the $\mathrm{ZnO}$ solution when the heating temperature was lower than $400^{\circ} \mathrm{C}$. As evidenced in a previous study, we observed infrared absorption bands for carboxylic groups after $\mathrm{ZnO}$ solutions had been calcined at temperatures lower than $300^{\circ} \mathrm{C} .{ }^{33}$

\section{Characterization of scattering sensing systems}

Based on their shapes and sizes, we believed that these $\mathrm{ZnO}$ nanoparticles would be suitable for the direct monitoring of targeted analytes that specifically adsorb onto and modify the light-scattering properties of the $\mathrm{ZnO}$ nanoparticles. To increase the effect of light scattering, the incident angle of the diode laser was first examined using a static detection system. As an example, Fig. 3A presents a typical plot of the dynamic signals detected after ethanol had been injected at a volume of $1 \mu \mathrm{L}$ utilizing static cell for detection; for this experiment, a $\mathrm{ZnO}$ sensor that had been prepared through calcination at $400^{\circ} \mathrm{C}$ for $1 \mathrm{~h}$ was used. Based on the intensity of the detected signal with respect to the detection time, the rate of detection was quite rapid, with the time required to reach maximum signals being ca. $1 \mathrm{~min}$. Considering the time delay necessary for evaporation of the ethanol sample, the real rate of detection was probably considerably shorter. To examine the influence of the incident angle, Fig. 3B presents the signals detected at a detection time of $5 \mathrm{~min}$ as a function of the incident angle. An angle of incidence of $c a .20^{\circ}$ provided detected signals having the highest intensity. Therefore, in the following experiments, the incident angle of the diode laser was maintained at $25^{\circ}$.

\section{Effect of calcination temperature}

To examine the effect of the calcination temperature on the light-scattering properties of the nanostructural materials, $\mathrm{ZnO}$ samples through 1-h calcination at various temperatures were prepared and used to detect ethanol by a static cell. The injected volume was $1 \mu \mathrm{L}$. Three sensing elements for each calcination temperature were prepared to obtain the standard deviation (plotted as error bars) of the signals. Figure 4A plots the signals 

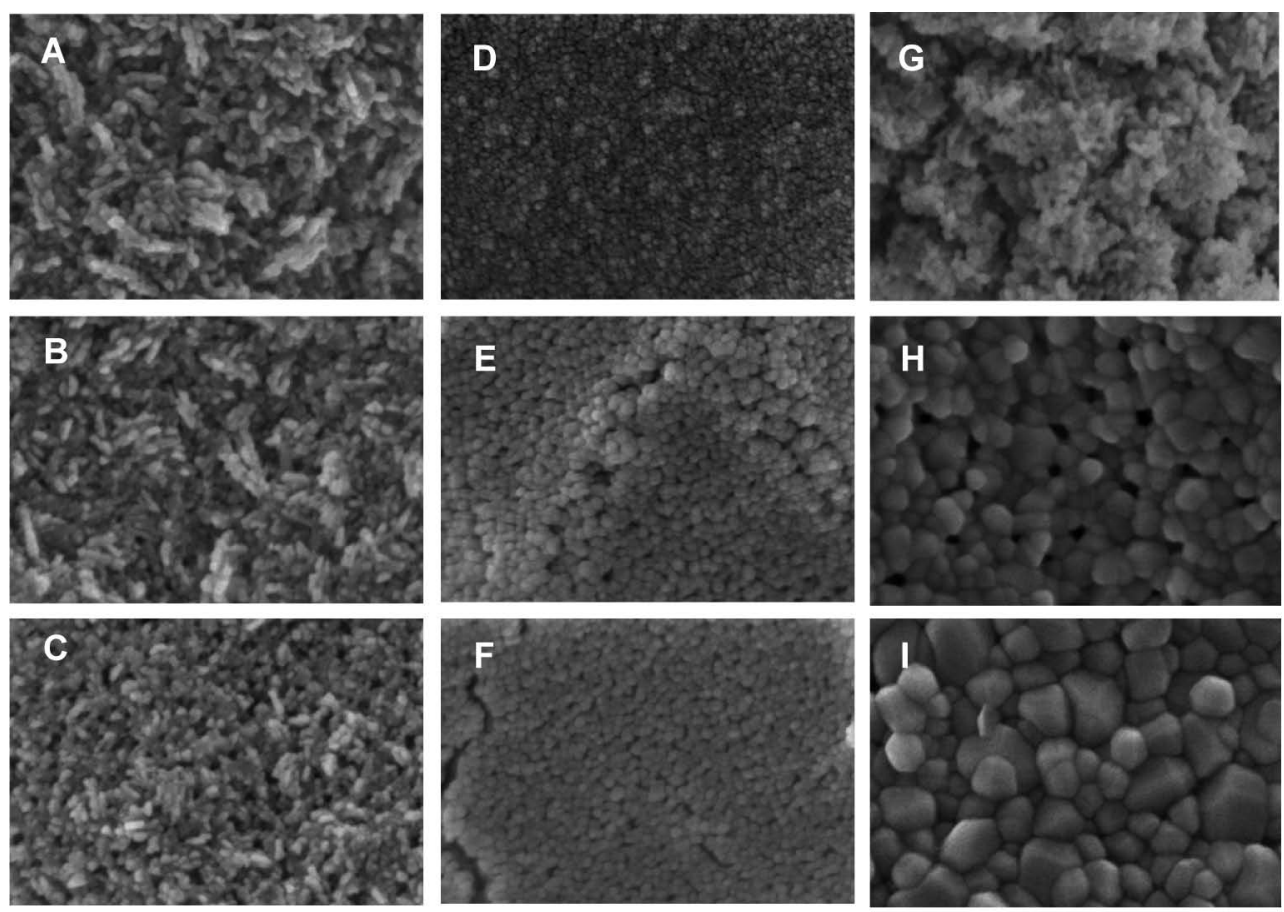

$\longmapsto 100 \mathrm{~nm}$

Fig. 2 SEM images of $\mathrm{ZnO}$ solutions calcined at $300^{\circ} \mathrm{C}$ for (A) 1 , (B) 1.5 , and (C) $2 \mathrm{~h}$ and at $400^{\circ} \mathrm{C}$ for (D) 1, (E) 1.5, and (F) $2 \mathrm{~h}$. SEM images of $\mathrm{ZnO}$ solutions calcined at temperatures of (G) 200, (H) 500 , and (I) $600^{\circ} \mathrm{C}$ for $1 \mathrm{~h}$.
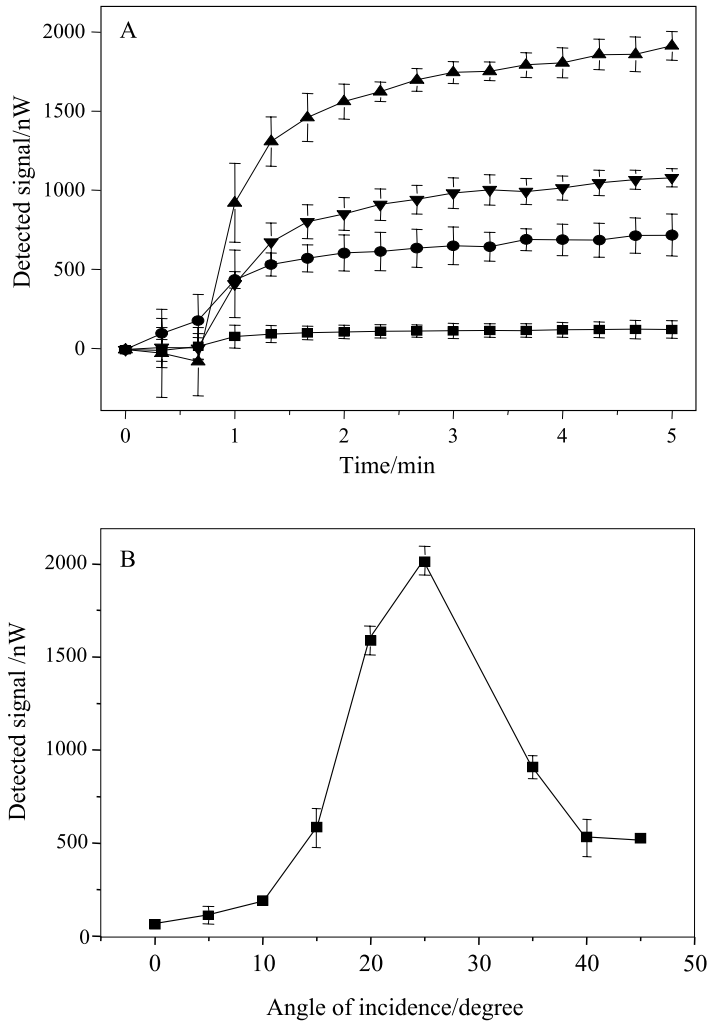

Fig. 3 (A) Time profiles for the detection of $1 \mu \mathrm{L}$ of ethanol after $20 \mu \mathrm{L}$ of $\mathrm{ZnO}$ solution had been calcined at $400^{\circ} \mathrm{C}$ for $1 \mathrm{~h}$. The angles of incidence of the diode laser were $5(\boldsymbol{\square}), 15(\boldsymbol{\bullet}), 25(\mathbf{\Delta})$, and $35^{\circ}$ $(\boldsymbol{\nabla})$. (B) Signals recorded at a detection time of $5 \mathrm{~min}$, plotted against the angle of incidence of the diode laser.
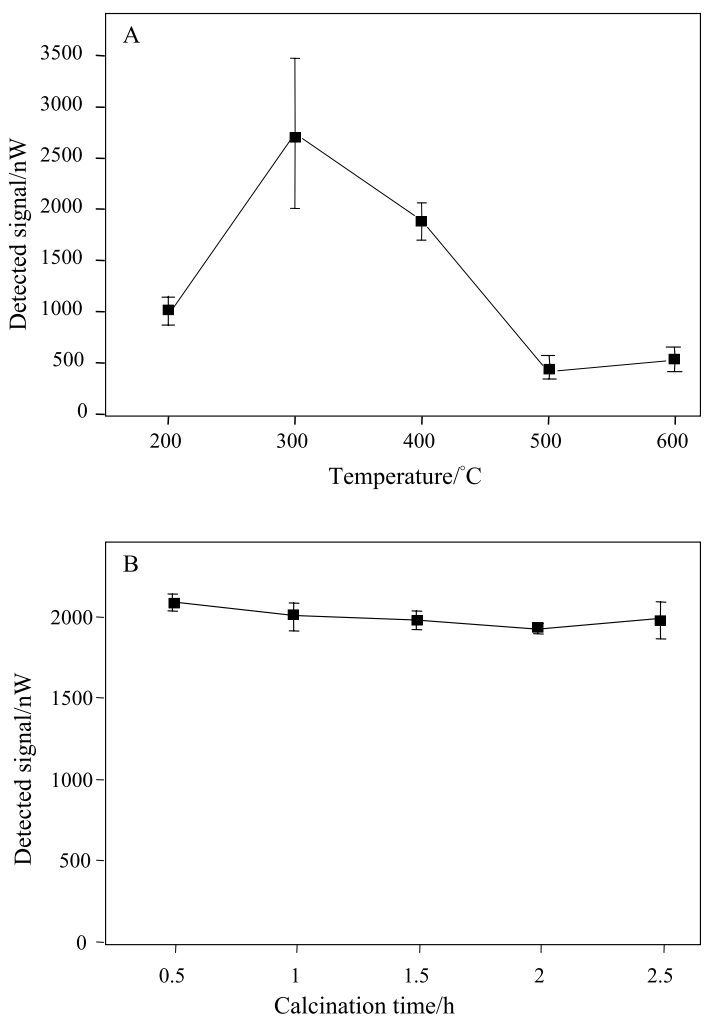

Fig. 4 (A) Signals of $1 \mu \mathrm{L}$ of ethanol recorded at a detection time of $5 \mathrm{~min}$, plotted against the calcination temperature. The sensor had been prepared from the calcination of $20 \mu \mathrm{L}$ of a $\mathrm{ZnO}$ solution for $1 \mathrm{~h}$. The angle of incidence of the diode laser was $25^{\circ}$. (B) Signals of $1 \mu \mathrm{L}$ of ethanol recorded at a detection time of $5 \mathrm{~min}$, plotted against the calcination time, for the sensor prepared from the calcination of $20 \mu \mathrm{L}$ of a $\mathrm{ZnO}$ solution at $400^{\circ} \mathrm{C}$. 

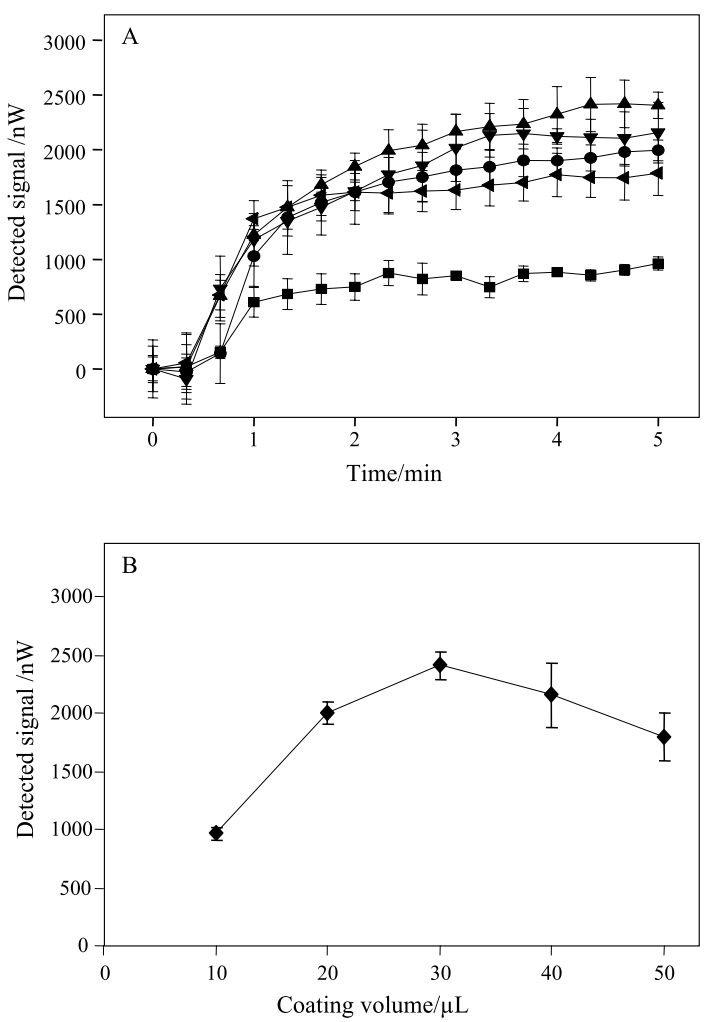

Fig. 5 (A) Time profiles for the detection of $1 \mu \mathrm{L}$ of ethanol using sensors calcined at $400^{\circ} \mathrm{C}$ for $1 \mathrm{~h}$ after coating with $10(\mathbf{\square}), 20(\bullet), 30$ (४), $40(\boldsymbol{\nabla})$, and $50 \mu \mathrm{L}$ ( $\mathbf{4})$ of the $\mathrm{ZnO}$ solution. (B) Signals of $1 \mu \mathrm{L}$ of ethanol recorded at a detection time of 5 min, plotted against the volume of the $\mathrm{ZnO}$ solution used for coating.

obtained after $5 \mathrm{~min}$ against the calcination temperature. Although the $\mathrm{ZnO}$ samples calcined at $300^{\circ} \mathrm{C}$ gave the highest-intensity signals, their reproducibility was the lowest among the tested samples. Based on these findings, it appeared that nanostructured $\mathrm{ZnO}$ materials possessing fiber-like forms would be most suitable for light-scattering measurements, but their low reproducibility might limit their applicability. The signals obtained at a calcination temperature of $400^{\circ} \mathrm{C}$ had lower intensity than those of the samples calcined at $300^{\circ} \mathrm{C}$, but much better reproducibility; the intensity of the signals decreased upon further increasing the calcination temperature. Based on our findings from the SEM measurements, the $\mathrm{ZnO}$ materials tended to form rounder nanoparticles with larger particle sizes as the calcination temperature was increased and, hence, a reduction of the scattering properties.

\section{Effect of calcination time and volume of coating}

To examine the effect of the calcination time, $\mathrm{ZnO}$ sensors were calcined by various durations at a temperature of $400^{\circ} \mathrm{C}$ and used to examine their analytical performances. Figure 4B presents a plot of the signals detected at $5 \mathrm{~min}$ after the injection of $1 \mu \mathrm{L}$ of ethanol. The signals obtained from each sensing element were similar. Based on Figs. 2D - 2F, the calcination temperature at $400^{\circ} \mathrm{C}$ resulted in films of having round-shaped $\mathrm{ZnO}$ nanostructures and the extending the calcination time did not alter the shape or size of these $\mathrm{ZnO}$ nanoparticles significantly. Thus, although the morphologies of these $\mathrm{ZnO}$ nanoparticles and the signals detected from them were both temperature-dependent, the duration of the calcination process had little effect on either of these properties.
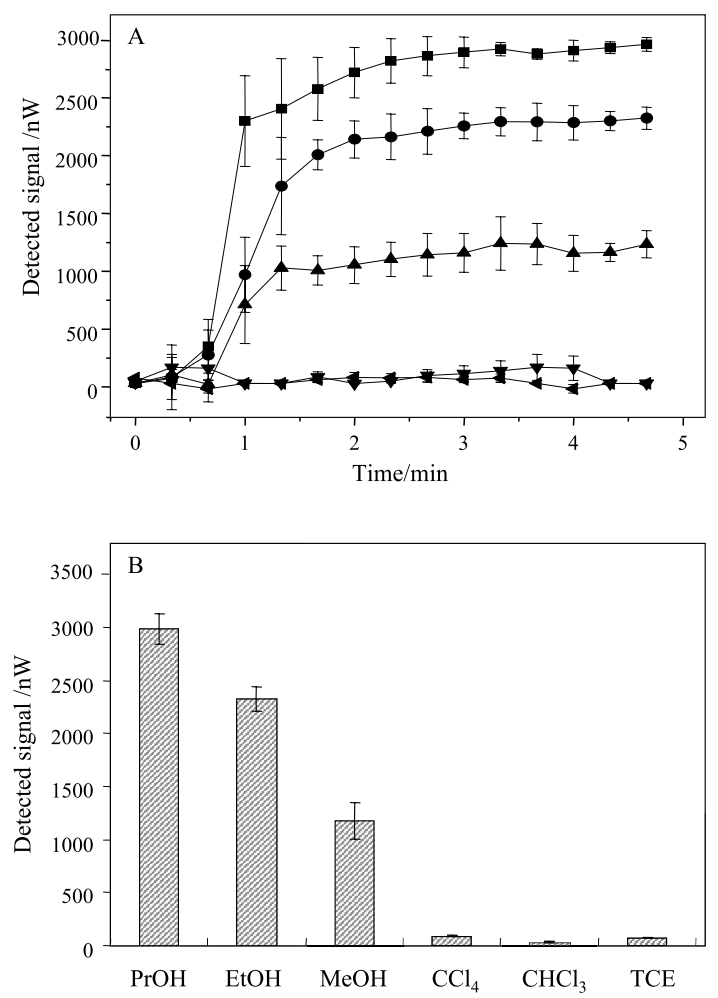

Fig. 6 (A) Detection time profiles of $1-\mu \mathrm{L}$ samples of methanol $(\boldsymbol{A})$, ethanol (@), propanol (ם), carbon tetrachloride (४), and trichloroethylene $(\boldsymbol{\nabla})$, using the sensor prepared through a process of coating with $30 \mu \mathrm{L}$ of the $\mathrm{ZnO}$ solution and calcining at $400^{\circ} \mathrm{C}$ for $2.5 \mathrm{~h}$. (B) Signals recorded at a detection time of $5 \mathrm{~min}$ for the examined VOCs.

The thickness of the $\mathrm{ZnO}$ layer on the surface of the sensing element is also an important parameter. For example, we expected that a thin layer of $\mathrm{ZnO}$ might result in a low degree of light scattering and, hence the changes to the scattering properties in the presence of the analyte might be too small to detect. On the other hand, a layer of $\mathrm{ZnO}$ that is too thick might also exhibit ineffective scattering of light. Therefore, we optimized the thickness of the $\mathrm{ZnO}$ layer by treating the surface of the sensing elements with different amounts of the $\mathrm{ZnO}$ solution while maintaining the length of the treated region at $6 \mathrm{~mm}$. After air-drying, we calcined these sensing elements at $400^{\circ} \mathrm{C}$ for $1 \mathrm{~h}$. Figure $5 \mathrm{~A}$ displays the time profiles for the detection of $1 \mu \mathrm{L}$ of ethanol using the sensors prepared with coating volumes ranging from 10 to $50 \mu \mathrm{L}$. A static cell was used in this study. The time required to reach the optimal signals was similar in each case, but the intensities varied with respect to the amount of coating. Figure $5 \mathrm{~B}$ presents the signals obtained after $5 \mathrm{~min}$ as a function of the coating volume. The signal of the sensing element coated with $30 \mu \mathrm{L}$ of the $\mathrm{ZnO}$ solution was the most intense.

\section{Selectivity in the detection of alcohols}

According to literature, ${ }^{21-31,33} \mathrm{ZnO}$ interacted uniquely with VOCs bearing hydroxyl groups. Therefore, in this study, the behaviors of our $\mathrm{ZnO}$ nanoparticles were examined their responses to six compounds (methanol, ethanol, propanol, TCE, carbon tetrachloride $\left(\mathrm{CCl}_{4}\right)$, and chloroform $\left(\mathrm{CHCl}_{3}\right)$ ) each injected at a volume of $1 \mu \mathrm{L}$ into the static cell. The sensing element for this study was prepared by coating with $30 \mu \mathrm{L}$ of 

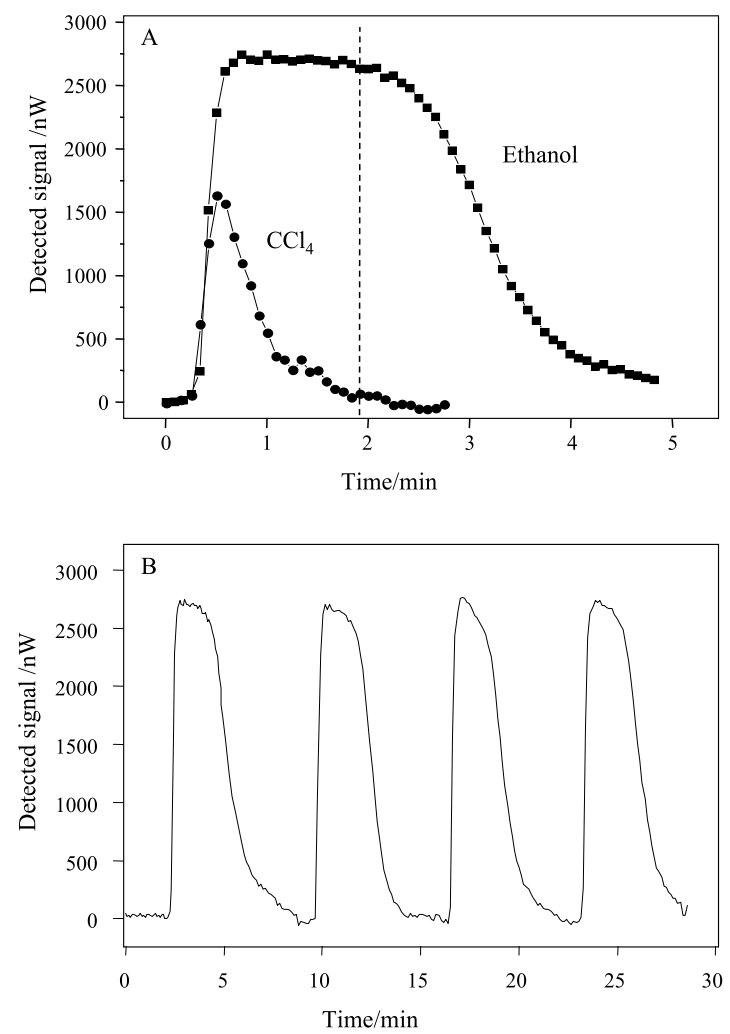

Fig. 7 Detection time profiles obtained using the flow cell-type system after (A) individual injections of $1 \mu \mathrm{L}$ of ethanol and $\mathrm{CCl}_{4}$ and (B) four consecutive injections of $1 \mu \mathrm{L}$ of ethanol.

the $\mathrm{ZnO}$ solution and then heating at $400^{\circ} \mathrm{C}$ for $2.5 \mathrm{~h}$. Figure $6 \mathrm{~A}$ provides the resulting response profiles for these compounds; Fig. 6B plots the signals obtained at a detection time of $5 \mathrm{~min}$. It is clear that the $\mathrm{ZnO}$ sensing element could detect the alcohols selectively, and that the responses toward the other three VOCs were too weak to interfere.

As can also be seen in Fig. 6B, the order of the selectivity among three alcohols is propanol $>$ ethanol $>$ methanol. This order can be explained by the electron donating-effect of gas molecule, as indicated by Cheng et al. ${ }^{26}$ For instance, the propanol bears a longer hydrocarbon chain than that of methanol, resulting in that the negative charge of the oxygen atom would increase with an increase of the electron-donating effect. Hence, the gas molecules are easier to be adsorbed on the film surface and the sensitivity increases.

\section{Flow-cell detection system}

To demonstrate that the type of light-scattering sensor developed in this study could be simplified further in terms of the detection procedure, a flow system was further constructed utilizing an air pump to pass the vaporized samples into the flow cell, as shown in Fig. 1B. After the injection of $1 \mu \mathrm{L}$ of a liquid sample into the sample vial and waiting for 5 min for complete evaporation, an air flow was used to purge the vaporized sample into the flow-cell device; the air flow rate was maintained at $15 \mathrm{~mL} / \mathrm{min}$. Figure 7A displays the typical response after one injection of neat ethanol and $\mathrm{CCl}_{4} ; \mathrm{Fig}$. 7B presents a plot of the response to a consecutive injection of ethanol. As is evident in Fig. 7A, the injection of $\mathrm{CCl}_{4}$ caused a rapid response in the first minute. As in the static system, the $\mathrm{ZnO}$-treated sensor exhibited no response toward $\mathrm{CCl}_{4}$; therefore, response of $\mathrm{CCl}_{4}$
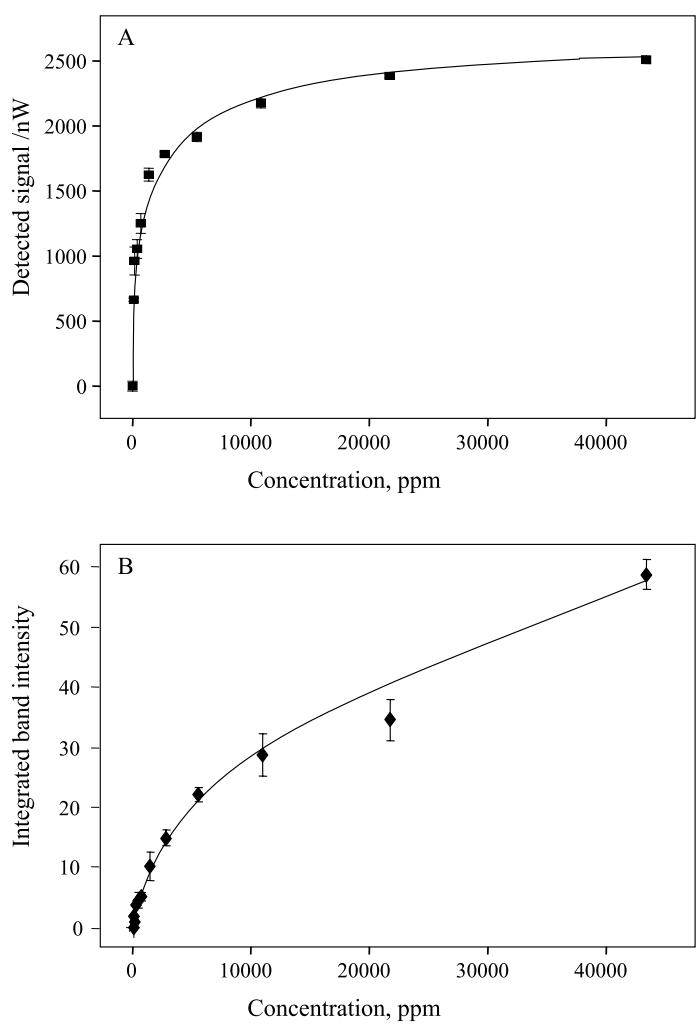

Fig. 8 Concentration-response curves for the detection of ethanol diluted in $\mathrm{CCl}_{4}$. The responses were calculated using the (A) time-delay and (B) band-area techniques. For the time-delay technique, the response at $110 \mathrm{~s}$ was selected to minimize the shearing effect, and used to plot against the concentration of ethanol. For the band-area technique, the area under the entire response in each injection was integrated and used to subtract the area when only $\mathrm{CCl}_{4}$ was injected. The subtracted values were plotted against the concentration of ethanol.

is most likely to be due to the flow pulse during the injection process (shearing effect). When comparing the band caused by this shearing effect with that of ethanol, the shearing effect could be completely eliminated when the analytical signals were recorded after a time delay of $c a .110 \mathrm{~s}$. When detecting a low concentration of ethanol, however, this time delay might not be feasible, because the rate of decay would be too fast to obtain an appropriate signal. Therefore, a method to extract the analytical signals was further developed and named the band-area technique. In this method, the responses during detection were integrated. By subtracting the integrated area of the response curve caused by the shearing effect (with injection of $\mathrm{CCl}_{4}$ only), the subtracted areas could be used to indicate the amount of ethanol and the concentration-response curves for quantitative purposes could be constructed. To obtain higher accuracy for the analysis, ethanol, was diluted in $\mathrm{CCl}_{4}$, and then $1 \mu \mathrm{L}$ of the diluted solution was injected. Figures $8 \mathrm{~A}$ and $8 \mathrm{~B}$ compare the results obtained using a time-delay the band-area techniques, respectively. For both cases, the linear range was limited to concentrations lower than $c a .200 \mathrm{ppm}$. Because there appears to be a bias in the curve for the time-delay technique, we suggest the use of the time-delay technique to obtain more-accurate quantitative results when the concentration of the analyte is relatively high. On the other hand, for low concentrations of analytes, the subtracted band-area technique appears to be more suitable for use. 


\section{Conclusion}

In this work, a light-scattering sensor that integrates the specific interactions between nanostructured $\mathrm{ZnO}$ materials and alcohols was developed. Both static and flow cell-type detection systems were performed. For the static sensing system, the effects of the parameters employed to prepare nanostructured $\mathrm{ZnO}$ materials for light scattering were investigated. Results indicated that $\mathrm{ZnO}$ nanoparticles formed when the calcination temperature was higher than $400^{\circ} \mathrm{C}$, with the calcination time having little influence on their morphologies. For calcination temperatures below $400^{\circ} \mathrm{C}$, the $\mathrm{ZnO}$ materials obtained possessed fiber-like shapes, for which the reproducibility in the detection of ethanol was worse than that of samples prepared at higher calcination temperatures. The thickness of the $\mathrm{ZnO}$ layer on the sensing element also influenced the analytical properties; the optimal conditions were obtained after $30 \mu \mathrm{L}$ of the $\mathrm{ZnO}$ solution had been applied to the sensing element. From a study of the response of a sensing element to various concentrations of ethanol and propanol, the detection behavior appeared to follow a surface adsorption mechanism with a linear range of up to $200 \mathrm{ppm}$. To accelerate the rate of detection, a flow cell-type sensing system was also constructed, which provided results similar to those of the static system, but with the time required to finish one sample being significantly reduced. Taken together, our results reflect the successful construction of a $\mathrm{ZnO}$-modified light scattering sensor that was selective for alcohols.

\section{Acknowledgements}

We thank the National Science Council of the Republic of China for supporting this study financially under Contract No. NSC98-2113-M-005-008-MY3.

\section{References}

1. Z. L. Wang, Materials Today, 2004, 7, 26.

2. L. Guo, S. Yang, C. Yang, P. Yu, J. Wang, W. Ge, and G. K. L. Wong, Chem. Mater., 2000, 12, 2268.

3. J. Yang, T. C. Deivaraj, H.-P. Too, and J. Y. Lee, Langmuir, 2004, 20, 4241.

4. X. Wang, C. J. Summers, and Z. L. Wang, Nano Lett., 2004, 4, 423.

5. Q. Kumar, V. Li, Y. Li, H. Zhang, T. J. Marks, and R. P. H. Chang, Chem. Mater., 2005, 17, 1001.

6. Y. R. Lin, Y.-K. Tseng, S.-S. Yang, S.-T. Wu, C.-L. Hsu, and S.-J. Chang, Cryst. Growth Des., 2005, 5, 579.

7. Y.-K. Tseng, C. J. Huang, H.-M. Cheng, I.-N. Lin, K.-S. Liu, and I.-C. Chen, Adv. Funct. Mater., 2003, 13, 811.
8. X. Y. Kong and Z. L. Wang, Nano Lett., 2003, 3, 1625.

9. Z. Gui, J. Liu, Z. Wang, L. Song, Y. Hu, W. Fan, and C. Chen, J. Phys. Chem. B, 2005, 109, 1113.

10. F. M. Hossain, J. Nishii, S. Takagi, T. Sugihara, A. Ohtomo, T. Fukumura, H. Koinuma, H. Ohno, and M. Kawasaki, Physica E, 2004, 21, 911.

11. M. S. Arnold, P. Avouris, Z. W. Pan, and Z. L. Wang, J. Phys. Chem. B, 2003, 107, 659.

12. H. Rensmo, K. Keis, H. Lindstorm, S. Sodergren, A. Solbrand, A. Hagfeldt, S.-E. Lindquist, L. N. Wang, and M. Muhammed, J. Phys. Chem. B, 1997, 101, 2598.

13. K. Westermark, H. Rensmo, H. Siegbahn, K. Keis, and A. Hagfeldt, J. Phys. Chem. B, 2002, 106, 10102.

14. L. Jing, J. Sun, J. Shang, W. Cai, Z. Xu, Y. Du, and H. Fu, Sol. Energy Mater. Sol. Cells, 2003, 79, 133.

15. D. Li and H. Haneda, Chemosphere, 2003, 51, 129.

16. D. Li and H. Haneda, J. Photochem. Photobiol., A, 2003 , $155,171$.

17. N. Koshizaki and T. Oyama, Sens. Actuators, B, 2000, 66, 119.

18. C. Xiangfeng, J. Dongli, A. B. Djurisic, and Y. H. Leung, Chem. Phys. Lett., 2005, 401, 426.

19. P. Nunes, E. Fortunato, A. Lopes, and R. Martins, Int. J. Inorg. Mater., 2001, 3, 1129.

20. G. Sberveglieri, S. Groppelli, P. Nelli, A. Tintinelli, and G. Giunta, Sens. Actuators, B, 1995, 25, 588.

21. G. S. T. Rao and D. T. Rao, Sens. Actuators, B, 1999, 55, 166.

22. T.-H. Kwon, S.-H. Park, J.-Y. Ryu, and H.-H. Choi, Sens. Actuators, B, 1998, 46, 75.

23. B. L. Zhu, C. S. Xie, W. Y. Wang, K. J. Huang, and J. H. $\mathrm{Hu}$, Mater. Lett., 2004, $58,624$.

24. Y. Anno, T. Maekawa, J. Tamaki, Y. Asano, and K. Hayashi, Sens. Actuators, B, 1995, 5, 623.

25. H. Nanto, T. Morita, H. Habara, K. Kondo, Y. Douguchi, and T. Minami, Sens. Actuators, B, 1996, 36, 384.

26. X. L. Cheng, H. Zhao, L. H. Huo, S. Gao, and J. G. Zhao, Sens. Actuators, B, 2004, 102, 248.

27. B. P. J. de L. Costello, R. J. Ewen, N. Guernion, and N. M. Ratcliffe, Sens. Actuators, B, 2002, 87, 207.

28. B. B. Rao, Mater. Chem. Phys., 2000, 64, 62.

29. F. D. Paraguay, M. Miki-Yoshida, J. Morales, J. Solis, W. L. Estrada, Thin Solid Films, 2000, 373, 137.

30. Q. Wan, Q. H. Li, Y. J. Chen, T. H. Wang, X. L. He, J. P. Li, and C. L. Lin, Appl. Phys. Lett., 2004, 84, 3654.

31. I. Stambolova, K. Konstantinov, S. Vassilev, P. Peshev, and Ts. Tsacheva, Mater. Chem. Phys., 2000, 63, 104.

32. J. Yang, Y.-R. Shih, I.-C. Chen, C.-I. Juo, and Y.-S. Huang, Appl. Spectrosc., 2005, 59, 1002.

33. G. G. Huang, C.-T. Wang, H.-T. Tang, Y.-S. Huang, and J. Yang, Anal. Chem., 2006, 78, 2397. 